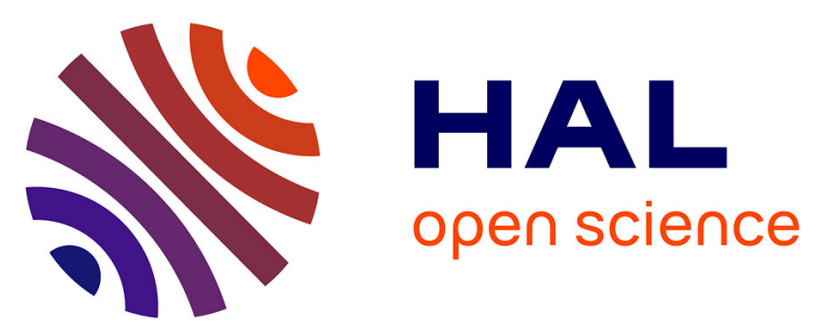

\title{
New polyurethanes based on 4,4'-diphenylmethane diisocyanate and 1,4:3,6 dianhydrosorbitol, 2. Synthesis and properties of segmented polyurethane elastomers
} Estelle Cognet-Georjon, Françoise Méchin, Jean-Pierre Pascault

\section{- To cite this version:}

Estelle Cognet-Georjon, Françoise Méchin, Jean-Pierre Pascault. New polyurethanes based on 4,4'diphenylmethane diisocyanate and 1,4:3,6 dianhydrosorbitol, 2. Synthesis and properties of segmented polyurethane elastomers. Macromolecular Chemistry and Physics, 1996, 197 (11), pp.3593-3612. 10.1002/macp.1996.021971109 . hal-02045951

\section{HAL Id: hal-02045951 https://hal.science/hal-02045951}

Submitted on 31 Mar 2020

HAL is a multi-disciplinary open access archive for the deposit and dissemination of scientific research documents, whether they are published or not. The documents may come from teaching and research institutions in France or abroad, or from public or private research centers.
L'archive ouverte pluridisciplinaire HAL, est destinée au dépôt et à la diffusion de documents scientifiques de niveau recherche, publiés ou non, émanant des établissements d'enseignement et de recherche français ou étrangers, des laboratoires publics ou privés. 


\title{
New polyurethanes based on 4,4'-diphenylmethane diisocyanate and 1,4:3,6 dianhydrosorbitol, $2^{\text {a) }}$ Synthesis and properties of segmented polyurethane elastomers
}

\author{
Estelle Cognet-Georjon, Francoise Méchin *, Jean-Pierre Pascault \\ Laboratoire des Matériaux Macromoléculaires, UMR CNRS 5627, \\ Institut National des Sciences Appliquées de Lyon, Bât. 403, \\ 20 avenue Albert Einstein, 69621 Villeurbanne Cedex, France
}

\section{SUMMARY:}

1,4:3,6-Dianhydrosorbitol (DAS) was used as chain extender in the preparation of new segmented polyurethane elastomers, based on polyoxytetramethylene or hydrogenated polybutadiene soft segments and 4,4'-diphenylmethane diisocyanate (MDI). These materials exhibit a two-phase microstructure, due to the thermodynamic immiscibility between hard and soft segments, which results in an elastomeric behavior over a wide temperature range. The thermal and dynamic mechanical properties of various formulations were then examined and related to the complex morphology of the corresponding (often semi-crystalline) materials. DAS leads to particularly stiff hard segments and provides longer rubbery plateaux, compared with a classical diol such as 1,4-butanediol. Phase separation is favored by longer and less polar soft segments. In any case, the structure of the materials strongly depends on the composition and synthesis procedure (bulk polycondensation leads to more heterogeneous samples), and most of all on the thermal history of the samples. This latter behavior is related to the existence of a possible order-disorder transition (ODT) which explains the change-over from a two-phase to a one-phase system after specific annealing experiments.

a) part 1: cf. ref. $^{8)}$ 


\section{Introduction}

Segmented polyurethanes form a wide range of high performance materials with tailorable properties. Although they are linear thermoplastic polymers, they usually exhibit an elastomeric behavior at room temperature, due to microscopic heterogeneities which result in the presence of physical crosslinks ${ }^{1,2)}$. Segmented polyurethanes are obtained by a one-stage, or more often two-stage terpolycondensation of a macroglycol (precursor of the "soft segment") with excess diisocyanate and a short diol (which lead to the "hard segment"). The two-phase microstructure is induced by the thermodynamic immiscibility between hard and soft segments ${ }^{1-5}$.

A growing interest is devoted to chemicals deriving from renewable resources as an alternative to oilbased monomers and raw materials. Among them, 1,4:3,6-dianhydrosorbitol (DAS) is available from starch in industrial quantities and although often used in pharmaceutics, could logically find the same kind of application as more common diols ${ }^{6,7)}$. In a previous work ${ }^{8)}$, we have shown that DAS could be a good candidate for the chain extension of segmented polyurethanes, since it conferred a remarkably high glass transition temperature $\left(T_{\mathrm{g}}\right)$ to the model hard segment based on 4,4'-diphenylmethane diisocyanate $\left(T_{\mathrm{g}}=190^{\circ} \mathrm{C}\right)$ while maintaining a reasonably low melting temperature $\left(T_{\mathrm{m}}=235^{\circ} \mathrm{C}\right)$. The use of DAS as chain extender should thus allow the preparation of thermally stable, but still easily processable block polyurethanes. The synthesis of the resulting materials based on poly(oxytetramethylene) or hydrogenated polybutadiene soft segments, together with their thermal and dynamic mechanical properties, are presented below.

\section{Experimental part}

\section{Materials}

Poly(tetramethylene oxide) (PTMO), molar mass 2000, 1000 or 650 from Aldrich Chemicals, and hydrogenated polybutadiene (HPBD), molar mass 2000 from Nippon Soda, were dried and degassed under vacuum one day at $60^{\circ} \mathrm{C}$. 4,4'-Diphenylmethane diisocyanate (MDI) was purchased from Bayer and used as received. 1,4:3,6-Dianhydrosorbitol (DAS) was a gift from Roquette Frères; it was recrystallized from methyl ethyl ketone and then dried under vacuum. Dibutyltin dilaurate (SnDBDL) from Merck, tetrahydrofuran (THF) and methanol from SDS were used without purification.

\section{Synthesis}

The materials investigated were polyurethane block copolymers; their chemical structure is shown in Fig. 1. The hard blocks were made from MDI, chain extended with DAS. The soft blocks (polyether segments) were based on PTMO, or occasionally on hydrogenated polybutadiene (HPBD) for comparison. The segmented copolymers were synthesized according to several two-stage processes: the first stage was a bulk polycondensation where PTMO was reacted with excess MDI at $80^{\circ} \mathrm{C}$ for $4 \mathrm{~h}$, under nitrogen and with mechanical stirring. The second stage could be either a bulk or a THF solution polycondensation where the chain extender DAS was added.

\section{a) second stage $=$ bulk polycondensation}

When the mixture had reached an adequate viscosity, it was degassed under vacuum with continuous stirring. After ten minutes, the reaction mixture was poured into a plate mould which was finally pressed at $100^{\circ} \mathrm{C}(100 \mathrm{bar}$ ) for $24 \mathrm{~h}$. The resulting polymer was translucent, nearly opaque. 
b) second stage $=$ THF solution polycondensation

Before adding DAS, the mixture was cooled at $50^{\circ} \mathrm{C}$ and then dissolved in THF (concentration by weight: $30 \%$ ). When the solution became clear, DAS and then SnDBDL catalyst ( $0.1 \mathrm{wt} .-\%$ with respect to the reactants as a whole) were added. The solution remained clear during all the reaction. After $3 \mathrm{~h}$, the polymer was precipitated in methanol and dried. The precipitation was redissolved in THF and a film could be obtained by evaporation.

Chemical products

MDI<smiles>O=[N+]([O-])c1ccc(Cc2ccc([N+](=O)[O-])cc2)cc1</smiles>

DAS<smiles>O[C@@H]1COC2C1OC[C@H]2O</smiles>

PTMO

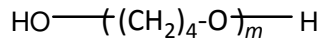

HPBD

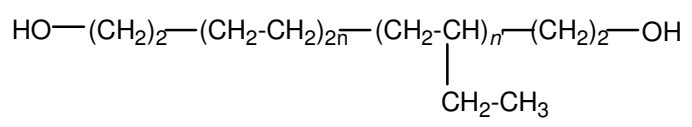

Segmented structure

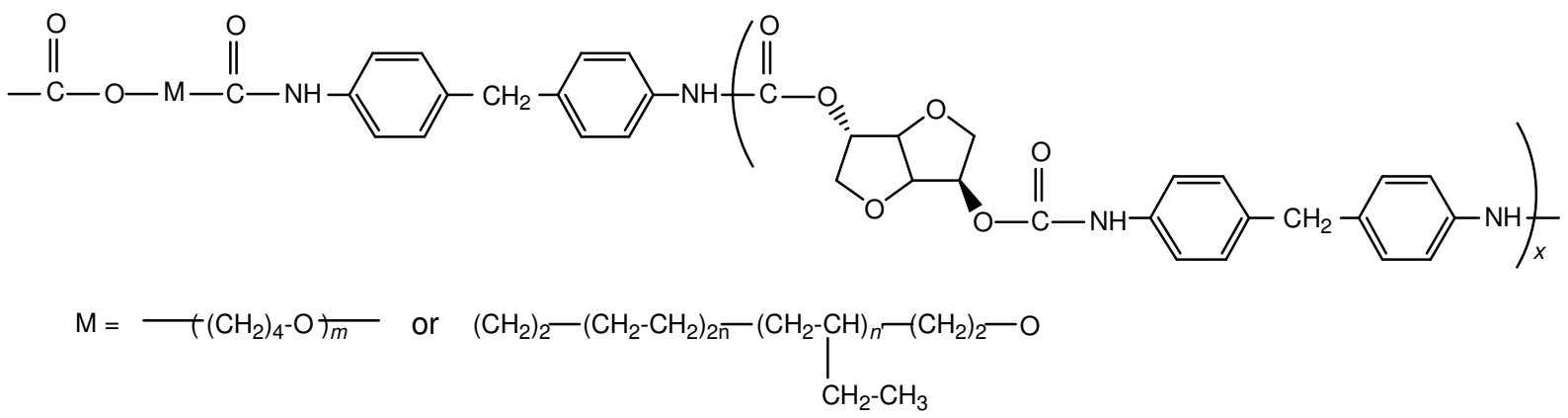

Fig. 1. Chemical structure of polyurethane block copolymers

In another way, the precipitate was placed in a plate mould and was pressed at $150^{\circ} \mathrm{C}(100$ bar) for 30 min.

\section{Nomenclature}

The molar ratio of PTMO, MDI and DAS was respectively $1 / 3 / 2$ or $1 / 5 / 4$, with an overall $\mathrm{NCO} / \mathrm{OH}$ ratio equal to 1. The molar mass of the starting PTMO was 2000,1000 or 650 . The polymers were referred to as PU followed by the kind of process ( $b$ for bulk, $f$ for film or $m$ for moulded precipitate), the polyether molar mass and finally the molar ratios of the three reactants. For instance PU, b 2 000 1/3/2 corresponds to the polyurethane prepared in bulk from 1 eq. of PTMO $\left(\overline{M_{n}}=2000\right)$, three eq. of MDI and two eq. of DAS.

Some polyurethanes were made from HPBD in stoichiometry $1 / 3 / 2(\mathrm{NCO} / \mathrm{OH}=1)$ and are referred to as PU, (f or $m$ ) HPBD. 


\section{Polymer characterization}

Size exclusion chromatography (SEC)

A Waters chromatograph was used with a 6000A pump, U6K injector, double detection (UV at $\lambda=254$ $\mathrm{nm}$ and differential refractometer R401). The eluent used was THF and the separation was carried out on four $\mu$-styragel columns $\left(10^{5}, 10^{4}, 10^{3}\right.$ and $\left.500 \AA\right)$.

\section{Differential scanning calorimetry (DSC)}

DSC measurements were made using a Mettler TA3000 apparatus under argon with a heating rate of $7.5 \mathrm{~K} / \mathrm{min}$. Samples were tested approximately 15 days after their preparation. The glass transition temperature of the soft segment $T_{\mathrm{gs}}$ was defined as the temperature of the onset of discontinuity in the heat capacity upon heating from the glassy amorphous state. For each sample, two scans were performed with a quench in liquid nitrogen after the first scan.

\section{Dynamic mechanical measurements}

Dynamic mechanical measurements were carried out using a Rheometrics RSA II analyzer. Rectangular samples were cut from films prepared by evaporation. Values of $E^{\prime}$ and $\tan \delta$ at various temperatures were obtained by stress-strain measurements at $1 \mathrm{~Hz}$. Temperatures were varied from -120 to $200^{\circ} \mathrm{C}$ and the heating rate was maintained at $2 \mathrm{~K} / \mathrm{min}$. 


\section{Results and discussion}

\section{Molar mass distribution}

Tab. 1 shows the different polyurethane formulations and their measured molar masses.

Tab. 1. SEC results for block polyurethanes PTMO/MDI/DAS synthesized in bulk or THF solution polycondensation using PTMO of different molar masses and different molar ratios, or HPBD. Comparison with PTMO/MDI/NPG block polyurethanes ${ }^{9)}$ synthesized in toluene solution (catalyst: SnDBDL)

\begin{tabular}{|c|c|c|c|c|c|c|}
\hline Sample & $\begin{array}{l}\text { DAS } \\
\text { amount } \\
\text { in wt.-\% }\end{array}$ & $\begin{array}{l}\text { Hard } \\
\text { segment } \\
\text { amount } \\
\text { in wt.-\% }\end{array}$ & ${\overline{M_{n}}}^{\text {a) }}$ & ${\overline{M_{w}}}^{\text {a) }}$ & $\frac{I_{p}}{\frac{M_{w}}{\bar{M}}}=$ & Film aspect \\
\hline$P U, f 6501 / 3 / 2$ & 17.3 & 61 & 22900 & 50800 & 2.2 & Clear \\
\hline PU, b 650 1/3/2 & 17.3 & 61 & 13200 & 92100 & 7.0 & Translucent \\
\hline PU f, 1000 1/3/2 & 14.3 & 51 & 16900 & 40900 & 2.4 & Clear \\
\hline$P U$, b 1000 1/3/2 & 14.3 & 51 & 17300 & 107500 & 6.2 & Translucent \\
\hline$P U, f 20001 / 3 / 2$ & 9.6 & 35 & 28200 & 74200 & 2.6 & Clear \\
\hline PU, b 2000 1/3/2 & 9.6 & 35 & 20200 & 141700 & 7.0 & Translucent \\
\hline$P U, f 2000$ 1/5/4 & 15.6 & 48 & 38600 & 146900 & 3.8 & Clear \\
\hline PU, b 2000 1/5/4b) & 15.6 & 48 & 9900 & 56300 & 5.7 & Translucent \\
\hline PTMO 1 000/MDI/NPG 1/2/1 & 0 & 37 & 23500 & 43300 & 1.8 & - \\
\hline PTMO 1 000/MDI/NPG 1/3/2 & 0 & 48 & 25300 & 61400 & 2.4 & - \\
\hline PU, f HPBD & 9.6 & 35 & 26100 & 264700 & 10 & Translucent \\
\hline
\end{tabular}

a) Polystyrene standards.

b) After chemical modification with trifluoroacetic anhydride.

c) From ref.9); samples prepared in catalyzed toluene solution.

\section{Comparison between bulk and solution polycondensation}

The three reactants, PTMO, MDI and DAS were initially miscible in bulk at $80^{\circ} \mathrm{C}$. The solution polycondensation in THF was homogeneous and the mixture remained clear during all the reaction. This indicates that macrophase separation and/or crystallization did not happen. On the contrary bulk polycondensation led to a final translucent material, whatever the molar mass of the starting PTMO. All the samples were soluble in THF, except PU, b 2000 1/5/4. The latter was only partially soluble in $\mathrm{THF}$, and a chemical modification of urethane groups by trifluoroacetic anhydride ${ }^{5,8,9)}$ was used in order to analyze its molar mass. Fig. 2 shows the SEC chromatograms of several polyurethanes synthesized either in bulk or in THF solution. We did not notice any modification on the chromatograms before and after precipitation in methanol for solution polycondensation: in both cases symmetrical curves are obtained.

For bulk polymerized samples, compounds with both lower and higher molar masses appear on chromatograms. The former look like isolated hard segments, since they are eluted after the starting polyether diol. A comparison with the chromatogram of pure MDI/DAS hard segments of low molar mass (obtained by the solution polycondensation of MDI and DAS (molar ratio: $3 / 2$ ) in THF) is also 
shown in Fig. 2 and tends to confirm this explanation. Ideally, the polydispersity index $\left(I_{\mathrm{p}}=\overline{M_{w}} / \overline{M_{n}}\right)$ of these samples should be close to 2.0 ; here, the higher $I_{\mathrm{p}}$ may be due to heterogeneity occurring during the reaction. The presence of isolated hard segments which could have crystallized within the material could also account for the translucent aspect of the samples prepared in bulk.

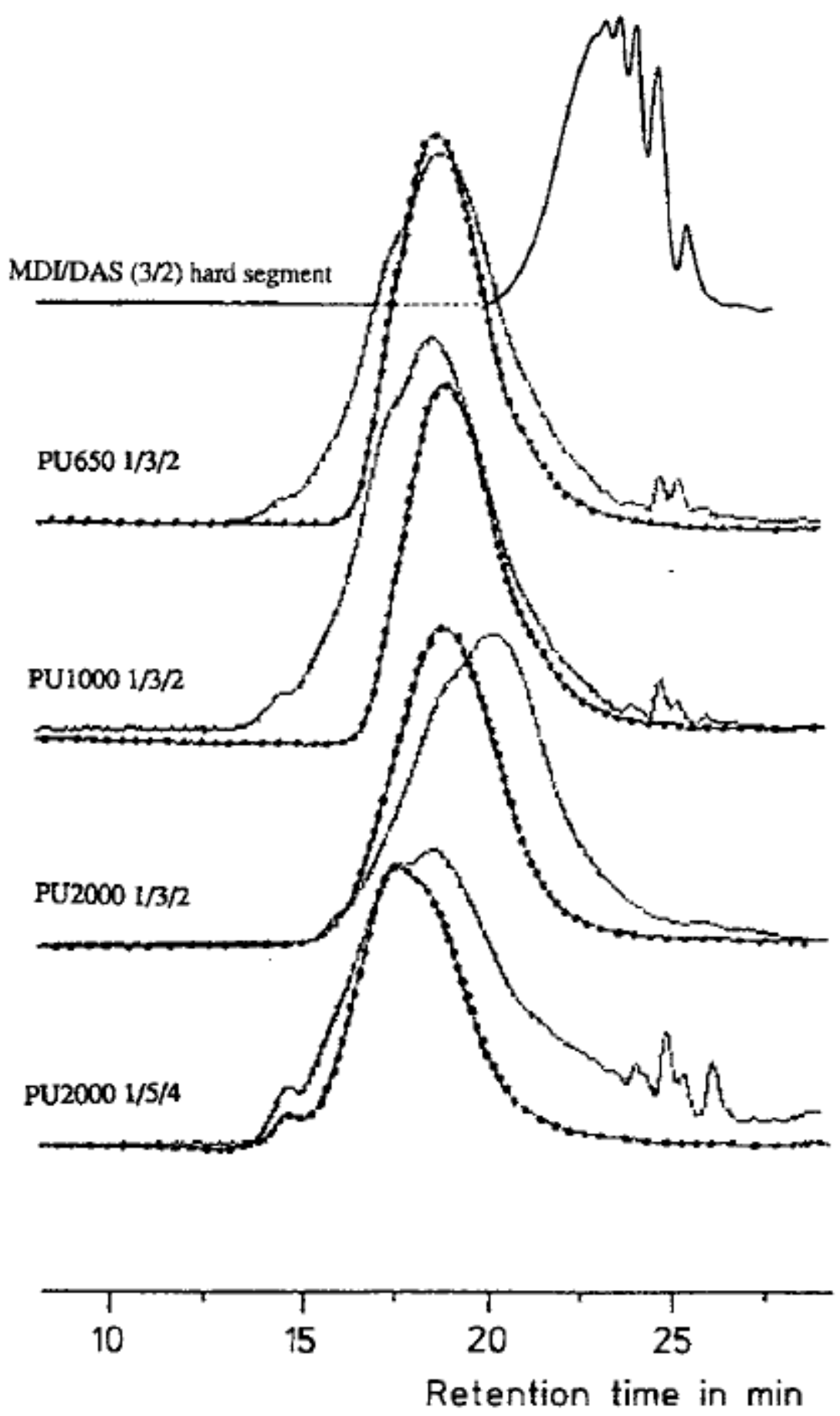

Fig. 2. SEC chromatograms of polyurethanes synthesized in bulk (-) or in solution condensation (-.---.-). Comparison with the hard segment obtained by solution polycondensation of MDI and DAS in THF (molar ratio: $3 / 2$ )

The difference between bulk and solution polymerization is the presence not only of a solvent, but also of a catalyst. It was shown by Bengtson et al..$^{3)}$ that when polycondensation reactions are performed 
in solution in a polar solvent, hydrogen bonds formed between urethane groups and solvent molecules induce a high solvation of the reactants and prevent phase separation. Moreover, Camargo et al. ${ }^{10)}$ pointed out the competition between phase separation and polymerization kinetics: a decrease in the catalyst content leads to higher polydispersities, as the molar masses are highly dependent on the polymerization rate (controlled mainly by the catalyst concentration). For RIM-processed polyurethanes based on poly(propylene oxide) diol, MDI and butanediol, an early crystallization of isolated hard segments with low molar masses was observed when no catalyst was used, whereas catalyzed procedures enabled reaction completion ${ }^{10}$. Therefore, in solution and in the presence of a catalyst the reaction can be over before the occurrence of a macrophase separation. Whereas in bulk, and especially using DAS, the reaction is slow because of its poorly reactive secondary hydroxyl groups. This would leave enough time for phase separation to occur, and would be consistent with the fact that isolated hard segments are formed and materials are only translucent, as opposed to the films obtained by solution polycondensation which are perfectly clear.

Tab. 1 finally shows that the molar masses observed here are similar to those obtained in a previous study ${ }^{9}$ on a PTMO/MDI/NPG (2,2-dimethyl-1,3-propanediol or neopentylglycol) system for which the hydroxyl groups of the chain extender are also sterically hindered.

\section{Thermal properties}

Representative DSC curves are shown in Figs. 3-6 for various stoichiometries and different ways of synthesis. After their synthesis, samples were kept at room temperature, and then cooled down to $120^{\circ} \mathrm{C}$ before a first DSC scan.

For each sample, several transitions can be analyzed. At low temperature, the first phenomenon is associated with the glass transition of the amorphous part of the semi-crystalline soft domain. The second region concerns the crystallization (exotherm) and melting (endotherm) of the crystalline part of the soft domain. The last phenomena, at higher temperature, are related to the hard segment domains.

\section{Soft domain analysis}

The glass transition temperatures $\left(T_{\mathrm{gs}}\right)$ of polyurethanes PU 1000 1/3/2 and PU 650 1/3/2 are not clearly marked, as opposed to PU $20001 / 3 / 2$ and $1 / 5 / 4$ for which they are well-defined. $T_{\mathrm{gs}}$ values reveal the relative purity of the soft domains: the presence of increasing amounts of contaminant (hard segment) leads to increasing $T_{\mathrm{gs}}$ for the soft polyether-rich domain. The degree of miscibility between hard and soft segments depends on their respective lengths and affinity for one another, and on the hard segment content. $T_{\mathrm{gs}}$ is raised when some hard segments are dissolved in the soft phase. 


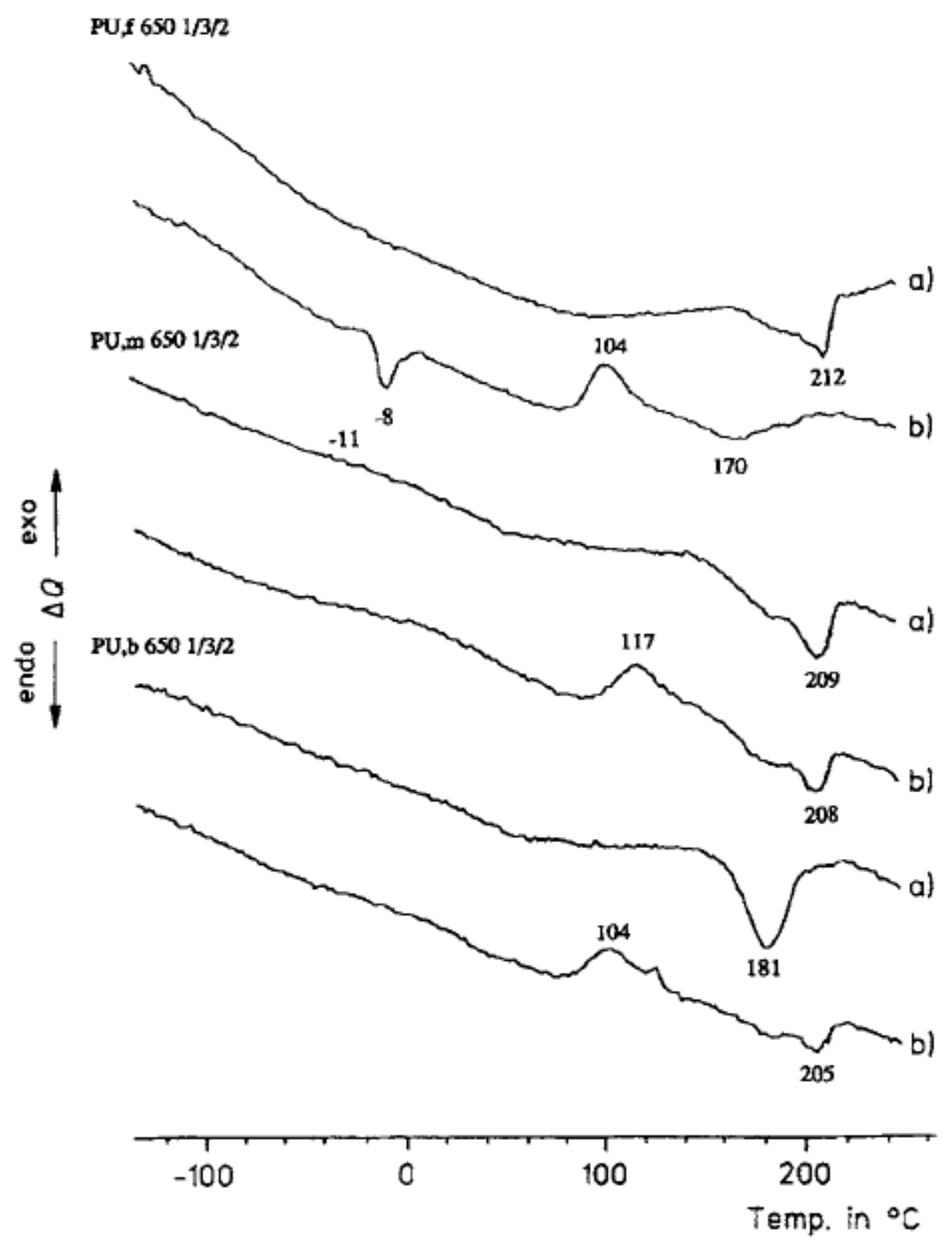

Fig. 3. DSC curves of segmented polyurethanes PU 650 1/3/2 prepared in different ways; (a) first scan; (b) second scan (after quench)

$T_{\mathrm{gs}}$ does not depend on the synthesis method. However after the first scan up to $230^{\circ} \mathrm{C}$, the samples were cooled down to $-120^{\circ} \mathrm{C}$ and a second DSC scan was performed. If we compare $T_{\mathrm{gs}}$ values determined from the first and second DSC scans, it appears that the latter are higher (see Figs. 5 and 6). Thus for this kind of samples, $T_{\mathrm{gs}}$ seems to be increased by successive melting and quenching, which would promote phase mixing and lead to less pure soft domains. A quite different behavior was observed for closely related samples based on hydroquinone bis(hydroxy-2-ethyl) ether (HQEE) as chain-extender ${ }^{9}$, for which a similar thermal treatment was shown to induce a reorganization of the hard segments followed by purification of the soft domains and a lower $T_{\mathrm{gs}}$. This difference may be attributed to a difference in miscibilities as well as to a higher ability of HQEE-based segments to crystallize. 


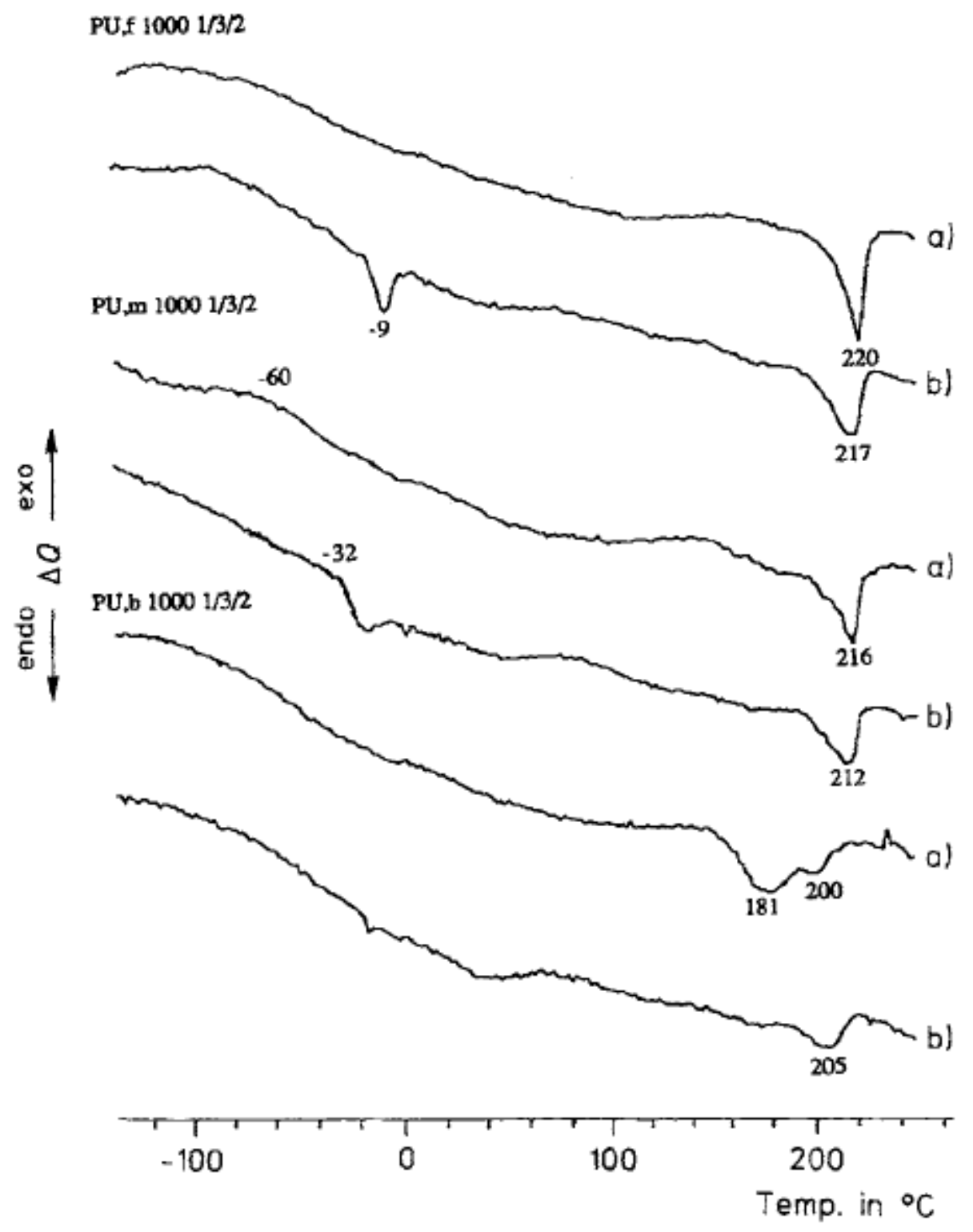

Fig. 4. DSC curves of segmented polyurethanes PU 1000 1/3/2 prepared in different ways; (a) first scan; (b) second scan (after quench)

Among the samples prepared in solution, the moulded samples $(\mathrm{m})$ undergo an additional thermal treatment with respect to the evaporated samples (f) since the former were pressed at $150^{\circ} \mathrm{C}$ for 30 min. However, the $T_{\mathrm{gs}}$ of $\mathrm{PU}, \mathrm{m} 1 / 3 / 2$ and $1 / 5 / 4$ are slightly lower or equal to the $T_{\mathrm{gs}}$ of the corresponding evaporated samples. This result corroborates those obtained with $\mathrm{HQEE}^{9}$ as well as the work of Hesketh et al. ${ }^{11)}$ with butanediol as chain extender. Heating the polyurethane leads to increased phase mixing but with time, some hard segments reorganize and demixing occurs. Such a mechanism was also suggested by Wilkes ${ }^{1,2)}$. Together with Rek and Govorcin ${ }^{12)}$, he also mentioned that for PTMO/MDI/1,4-butanediol samples, a shift in $T_{\mathrm{gs}}$ towards higher temperatures was observed immediately after annealing and quenching, but $T_{\mathrm{gs}}$ shifted back towards low temperatures after a determined postquench time. By ESR experiments on the same polymers, Chen et al. ${ }^{13)}$ even demonstrated that the samples having higher soft segment molar mass had a faster demixing process than their counterpart with lower $\overline{M_{n}}$ [PTMO]. In our experiments, hard segments did not have enough 
time for demixing between two DSC scans, whatever the polyether molar mass, and we observed a slight miscibility of the phases.

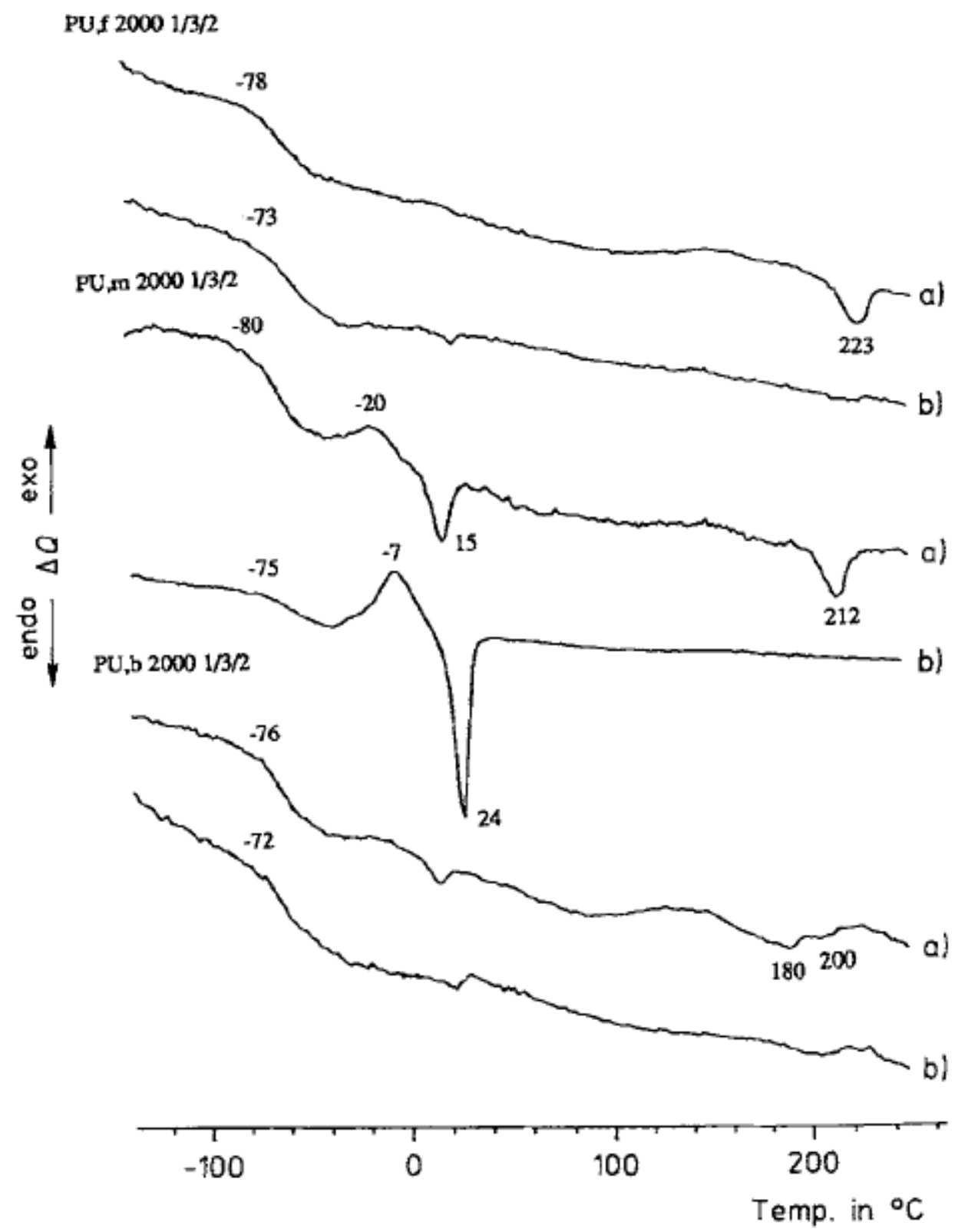

Fig. 5. DSC curves of segmented polyurethanes PU 2000 1/3/2 prepared in different ways; (a) first scan; (b) second scan (after quench)

For a given stoichiometry $1 / 3 / 2$, a decrease in the molar mass of the starting polyether involves an increase in the overall hard segment content. In any case, a difference appears between $T_{\mathrm{g}}$ of the pure PTMO and $T_{\mathrm{gs}}$ associated with polyurethane soft domains. The reason for this increase can be found in two facts:

i) contamination by dissolved high- $T_{\mathrm{g}}$ hard segments. According to Koberstein and co-workers ${ }^{14,15)}$, there would be a critical hard sequence length below which hard segments would dissolve in the soft phase, whereas longer ones would segregate into a microdomain structure. 
ii) restriction of the mobility of the polyurethane soft segment at the hard/soft junction, either because the hard domains act as physical crosslinks or simply because the polyether chain ends have been chemically modified ${ }^{16)}$.

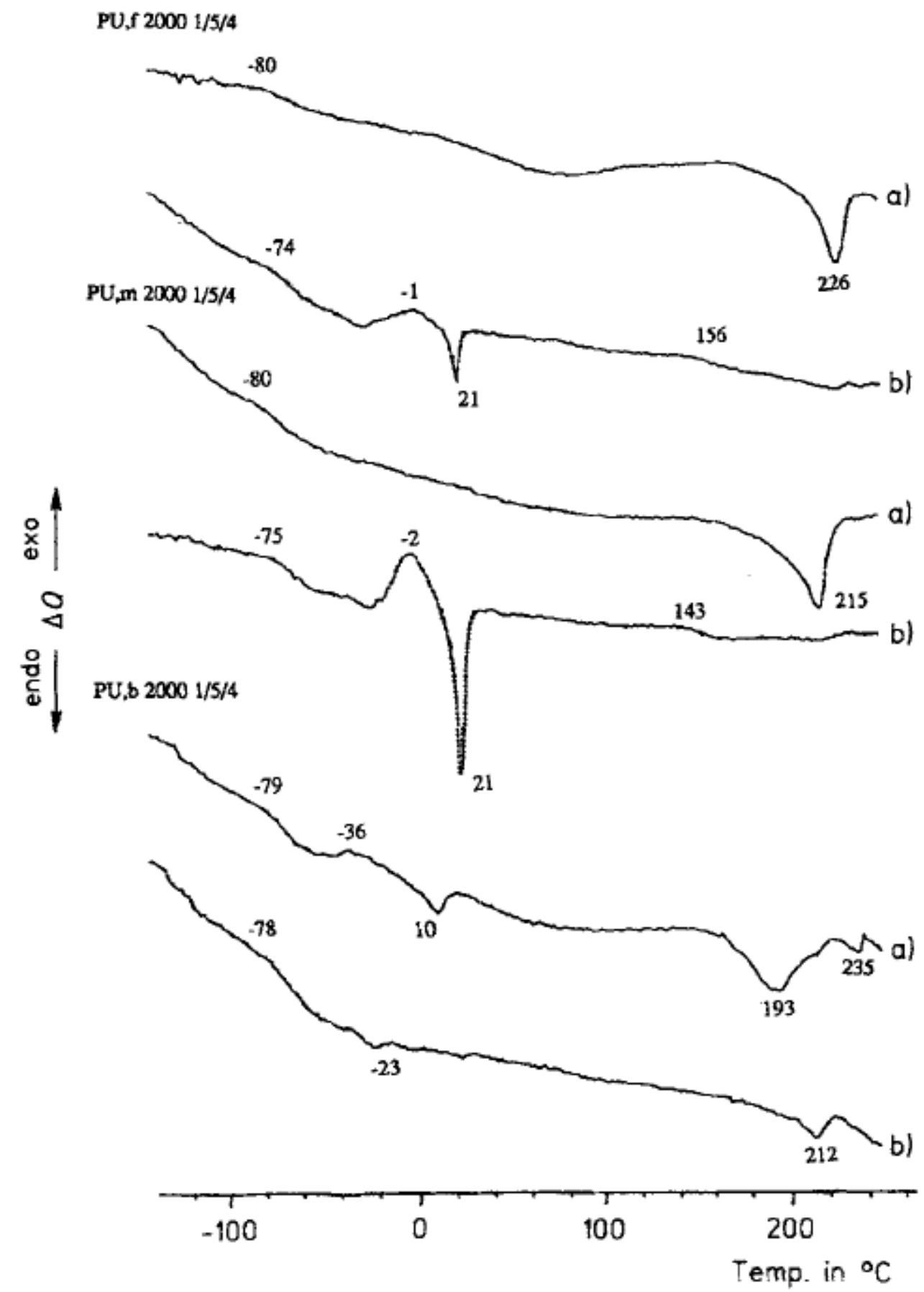

Fig. 6. DSC curves of segmented polyurethanes PU 2000 1/5/4 prepared in different ways; (a) first scan; (b) second scan (after quench)

Tab. 2 gives the different values of $T_{\mathrm{gs}}$ and compares them with the associated $T_{\mathrm{gPTMO}}$. The difference between them is small for $\overline{M_{n}}$ [PTMO $]=2000\left(T_{\mathrm{gs}}-T_{\mathrm{gPTMO}}=11 \mathrm{~K}\right)$ and can be associated with a simple restriction of mobility (in the literature, Chen et al. report an increase of $14 \mathrm{~K}$ for the $T_{\mathrm{g}}$ of amineterminated poly(oxypropylene), simply once it has been reacted with phenylisocyanate ${ }^{16)}$ ). For shorter 
polyethers, the difference is much larger and probably due to the presence of dissolved hard segments, also revealed by the fact that in this case $T_{\mathrm{gs}}$ is not clearly marked.

Tab. 2. $T_{\mathrm{gs}}$ values for the polyurethane soft domains. Comparison with the pure PTMO oligomer $\left(T_{\text {gPTMO }}\right)^{\text {a) }}$

\begin{tabular}{|c|c|c|c|c|}
\hline$\overline{M_{n}}$ [PTMO] & $\overline{\overline{D P_{n}}}$ & $T_{\mathrm{gPTMO}} /{ }^{\circ} \mathrm{C}$ & $T_{\mathrm{gs}} /{ }^{\circ} \mathrm{C}^{\mathrm{b})}$ & $\left(T_{\mathrm{gs}}-T_{\mathrm{gPTMO}}\right) /{ }^{\circ} \mathrm{C}$ \\
\hline 2000 & 27.8 & -91 & -80 & 11 \\
\hline 1000 & 13.9 & -94 & -60 & 34 \\
\hline 650 & 9.0 & -95 & -11 & 84 \\
\hline
\end{tabular}

a) $T_{\mathrm{gs}}$ : glass transition temperature of the soft domain of PTMO/MDI/DAS polyurethanes; $T_{\mathrm{gPTMO}}$ : glass transition temperature of the starting oligomer.

b) For "PU, m 1/3/2" samples (prepared in solution, moulded precipitate).

PU $20001 / 3 / 2$ and 1/5/4 differ from one another in their hard segment length and content (respectively 35 wt.-\% and 48 wt.-\%). However, for both kinds of samples the segregation rate (as estimated by the value of $T_{\mathrm{gs}}$ ) is important. This would mean that phase separation would be roughly independent of the hard segment content and length but that the limitative factor would rather be the length of the soft segment (i. e. $\overline{M_{n}}$ [PTMO]). There is apparently no difference between dianhydro-Dsorbitol and 1,4-butanediol (BDO) as far as phase separation is concerned.

The exotherm due to the soft segment crystallization and the endotherm due to its melting appear only when $\overline{M_{n}}$ [PTMO $]=2000$. In this case, the semi-crystalline character of the polyurethane soft domain proves its purity and thus a high segregation rate (no dissolved hard segments). It was reported for PTMO/MDI/BDO systems ${ }^{13,17)}$ that soft segment crystallinity was generally not observed if $\overline{M_{n}}$ [PTMO] $<1000$. In fact, this observation is valid for segmented polyurethanes containing about $50 \mathrm{wt}$.$\%$ hard blocks. For lower hard block contents, their filler effect is less pronounced and crystallization is allowed even for lower soft segment molar masses. But in our case, the polyurethanes based on PTMO 1000 and 650 contain respectively 51 wt.-\% and 61 wt.-\% hard blocks.

Nevertheless, the crystallinity of the soft domain is better defined during the second DSC scan, even though $T_{\mathrm{gs}}$ is then slightly higher. A thermal treatment enhances crystallization and shifts the exotherm and endotherm towards higher temperatures. These phenomena can be correlated with $T_{\mathrm{gs}}$; during the second scan, $T_{\mathrm{gs}}$ is higher and thus crystallization is delayed. But on the other hand, the higher temperature provides a larger driving force for crystallization; nucleation occurs in a large number of sites and crystallization is accelerated. Therefore, both the exotherm and the following melting endotherm are more intense.

\section{Hard domain analysis}

PU 2000 1/3/2 and 1/5/4 differ by their hard segment contents (respectively 35 and 48 wt.-\%). PU $20001 / 5 / 4$ have longer hard segments, and although both types of polyurethanes present an important phase separation (see Figs. 5 and 6), PU, f and PU, $m 2000$ 1/3/2 do not show any transition in the second DSC scan whereas PU, f and PU, $\mathrm{m} 20001 / 5 / 4$ present a glass transition, $T_{\mathrm{gh} .} T_{\mathrm{gh}}=156^{\circ} \mathrm{C}$ for PU, f $20001 / 5 / 4$ and $143^{\circ} \mathrm{C}$ for PU, m 2000 1/5/4. These data are slightly lower than those obtained for the model hard segment synthesized with a ratio $\mathrm{NCO} / \mathrm{OH}=1 / 1$ which presented a glass 
transition at $187^{\circ} \mathrm{C}$ in the second DSC scan ${ }^{8}$. This suggests the presence of dissolved soft segments in the hard domain, presumably due to non-equilibrium entrapment of the soft sequences of the multiblock chain. However, the difference is still reasonable for a highly segregated polyurethane. Here the important segregation rate, together with the relatively high hard block content allow the detection of $T_{\mathrm{gh}}$, but it was not possible to determine quantitative $\Delta C_{\mathrm{p}}$ values for the apparent hard microdomain glass transition of the moulded polyurethanes; they are nevertheless considerably smaller than what would be calculated from the pure hard segment values ${ }^{8)}$. This can be due to some degree of hard segment crystallinity and ordering and also to the inclusion of some hard segments within the soft phase.

As shown above, the segregation rate depends on the length of the starting PTMO. PU 2000 1/3/2 presents phase separation while PU 1000 and 650 1/3/2 exhibit phase mixing: some hard blocks are dissolved in the soft phase, but probably also some soft segments in the hard phase which were trapped during structure formation. But in neither case is a glass transition ever detectable for polyurethane hard domains (in the range $150-180^{\circ} \mathrm{C}$ ).

Bulk and solution-prepared polyurethanes based on PTMO 2000 do not show the same behavior (see Fig. 5). But all of them present a well-defined high-temperature melting endotherm during their first DSC scan, which implies that although the solution-prepared samples are clear, they must nevertheless contain a comparable amount of crystalline zones; yet their size must be very small. For these samples synthesized in solution (PU, $f$ and PU, $m$ ), the melting is no longer detected in the second DSC scan. They have then the same behavior as the model hard segment based on DAS and $\mathrm{MDI}^{8}$. However, they show only one endotherm: PU, f $20001 / 3 / 2$ at $223^{\circ} \mathrm{C}$, and PU, $\mathrm{m} 20001 / 3 / 2$ at $212^{\circ} \mathrm{C}$; whereas the model hard segment with $\mathrm{NCO} / \mathrm{OH}=3 / 2$ displayed three melting endothems, which were attributed to different chain lengths, considering the molar mass distribution detected by SEC $^{8)}$. The melting endothem of PU, f 2000 1/3/2 looks more like that of the model hard segment prepared with NCO/OH $=1$. The latter exhibited a gaussian-like mass distribution and only one melting endotherm at $235^{\circ} \mathrm{C}^{8)}$. As there were no low molar mass species in PU, f 2000 1/3/2 (no isolated hard segment, as shown in Figure 2), the multiple melting endotherms seem to be due to these isolated hard segments: it would be consistent with the results found for the sample obtained in bulk, PU, b 2000 1/3/2, which displays two melting endotherms at $180^{\circ} \mathrm{C}$ and $200^{\circ} \mathrm{C}$ (Fig. 5) and low molar mass species in its SEC chromatogram (Fig. 2) which can be attributed to isolated (i.e. non-linked) hard segments.

In the literature ${ }^{18-20)}$, the existence of multiple melting endotherms was at first attributed to the disordering of hard segments with different degrees of order. More recently, DSC and SAXS experiments on segmented polyurethanes led Koberstein, Ryan and co-workers ${ }^{21-23)}$ to introduce the notion of order-disorder transition, which can occur during polyurethane processing or annealing. The order-disorder transition (ODT) or microphase separation transition (MST) is well-known for diblock copolymers and consists in a thermodynamic transition from an initial ordered (i. e. microphaseseparated) state into a homogeneous disordered state. Former results ${ }^{18)}$ could be reinterpreted in terms of ODT temperatures. Koberstein et al. ${ }^{20)}$ showed that in a DSC scan performed after annealing at a given temperature, intermediate endotherms could be attributed to the disruption of microdomain structures and partial intersegmental mixing occurring at the ODT temperature. Above the ODT, crystallization of the hard segments occurs from a homogeneous medium and can be seen as a "solution" crystallization process, whereas below the ODT (but still above $T_{\mathrm{gh}}$ ) it would occur inside the hard microdomains and could thus be seen as a bulk crystallization process ${ }^{20)}$. In this respect the thermal properties of the materials strongly depend on their processing temperature ${ }^{15,21 a)}$. On studying 
polyurethanes prepared by RIM followed by compression-moulding at $200^{\circ} \mathrm{C}$, and containing $50 \%$ amorphous hard segments, Ryan and coworkers ${ }^{23}$ observed by DSC an initially well segregated microstructure with two glass transition temperatures corresponding to both types of segments, and a low magnitude thermal transition at $\approx 150^{\circ} \mathrm{C}$ which could be attributed to the ODT. However, once heated above the ODT and then quenched, only one intermediate glass transition was detected, which corresponded to a homogeneous block copolymer and confirmed the former observations in the literature.

In our case, the ODT is somewhat difficult to assign. However for all bulk-prepared samples, an intermediate endotherm is detected in the first DSC scan (at $181^{\circ} \mathrm{C}$ for all PU, b $1 / 3 / 2$ and $193^{\circ} \mathrm{C}$ for PU, b $20001 / 5 / 4$, i.e. in the same range or slightly higher than the $T_{\mathrm{g}}$ of the pure MDI/DAS polyurethane, $187^{\circ} \mathrm{C}$ ) which could correspond to this transition. According to Koberstein, the ODT temperature depends on (and increases with) the average hard segment length and should thus be associated here with the initial MDI/DAS stoichiometry; the fact that the same value is found for all $1 / 3 / 2$ samples whereas it is higher for a $1 / 5 / 4$ stoichiometry would corroborate the attribution of this endotherm.

The existence of an ODT could also explain the second DSC scans of PU 650 and 1000 1/3/2. The quench from above the ODT after the first scan would maintain the polyurethane in a homogeneous state; during the second scan, there is actually only one glass transition followed by a crystallization exotherm and finally a melting endotherm. Assuming complete miscibility between hard and soft segments, this $T_{\mathrm{g}}$ should follow Fox's equation:

$$
\frac{1}{T_{\mathrm{g}}}=\frac{x_{\mathrm{s}}}{T_{\mathrm{gs}}}+\frac{x_{\mathrm{h}}}{T_{\mathrm{gh}}}
$$

where $x_{\mathrm{s}}$ and $x_{\mathrm{h}}$ represent the weight fractions of the soft and hard segments, respectively. and $T_{\mathrm{g}} T_{\mathrm{gs}}$ and $T_{\mathrm{gh}}$ stand for the glass transition temperatures of the polyurethane and of the pure soft and hard segments, respectively. For PU $10001 / 3 / 2$, this theoretical $T_{\mathrm{g}}$ is equal to $-13^{\circ} \mathrm{C}$ whereas it would be $11^{\circ} \mathrm{C}$ for PU $6501 / 3 / 2$. Although the glass transition is somewhat difficult to detect in the second DSC scans, they can be estimated around $-32^{\circ} \mathrm{C}$ for $\mathrm{PU}, \mathrm{m} 10001 / 3 / 2$ and around $13^{\circ} \mathrm{C}$ for $\mathrm{PU}, \mathrm{m} 650$ 1/3/2. This would indicate a partial miscibility in the case of PU, $m 1000$ 1/3/2 whereas this miscibility would be practically complete in the case of $\mathrm{PU}, \mathrm{m} 650$ 1/3/2.

For PU $20001 / 3 / 2$ and 1/5/4, the presence of the ODT is not as well confirmed by the second DSC scan since despite the quench $T_{\mathrm{gs}}$ is only slightly higher. Between the first scans of PU, f $20001 / 3 / 2$ and PU, $m 2000$ 1/3/2, the melting endotherm is shifted towards lower temperatures. A similar observation can be made for $\mathrm{PU}, \mathrm{f}$ and $\mathrm{PU}, \mathrm{m} 1000$ 1/3/2. PU, $\mathrm{m}$ samples cured at $150^{\circ} \mathrm{C}$ whereas the maximum temperature for $\mathrm{PU}, \mathrm{f}$ samples was much lower.

Yang et al. ${ }^{24)}$ reported a possible thermal degradation of urethanes based on MDI and BDO; the urethane bond was unstable above $170^{\circ} \mathrm{C}$. Camberlin and coworkers ${ }^{25}$ demonstrated that an isomolecular hard segment based on $\mathrm{MDI}$ and $\mathrm{BDO}$ was changed into a mixture of shorter and longer chains when heated up to $220^{\circ} \mathrm{C}$. A polymerization/depolymerization competition seemed to be responsible for this broadening of the molar mass distribution and could also explain the behavior of our PU, $\mathrm{m}$ samples. These rearrangements have also been reported to be favored by the presence of a catalyst ${ }^{26)}$ and could account for some of the phenomena observed in the second DSC scans of solution-prepared samples. Transurethanization was said to proceed via a four-center type reaction ${ }^{26)}$, which in consideration of the particular spatial structure of isosorbide would seem less favored. 
However, our former studies on model [-MDI-DAS $]_{n}$ hard segments also suggest the existence of such rearrangements during the first DSC scans, and although deeper investigations would be necessary, it is thus difficult to discuss the second DSC scans more thoroughly.

\section{Dynamic mechanical properties}

Samples were tested by stress-strain measurements at $1 \mathrm{~Hz}$ (temperature sweep). The curves storage modulus $\left(E^{\prime}\right)$ vs. temperature and $\tan \delta$ vs. temperature obtained with various segmented polyurethanes are shown in Figs. 7 and 8 . The measurements were performed on the films prepared by evaporation of the THF solutions.

Peaks are observed on the tan $\delta$ vs. temp. curves at about $-100^{\circ} \mathrm{C},-52^{\circ} \mathrm{C}, 100^{\circ} \mathrm{C}$ and $190^{\circ} \mathrm{C}$. They are referred to as $\gamma, \alpha_{s}, \alpha_{h}$ and $\delta$, respectively, and are summarized in Tab. 3.

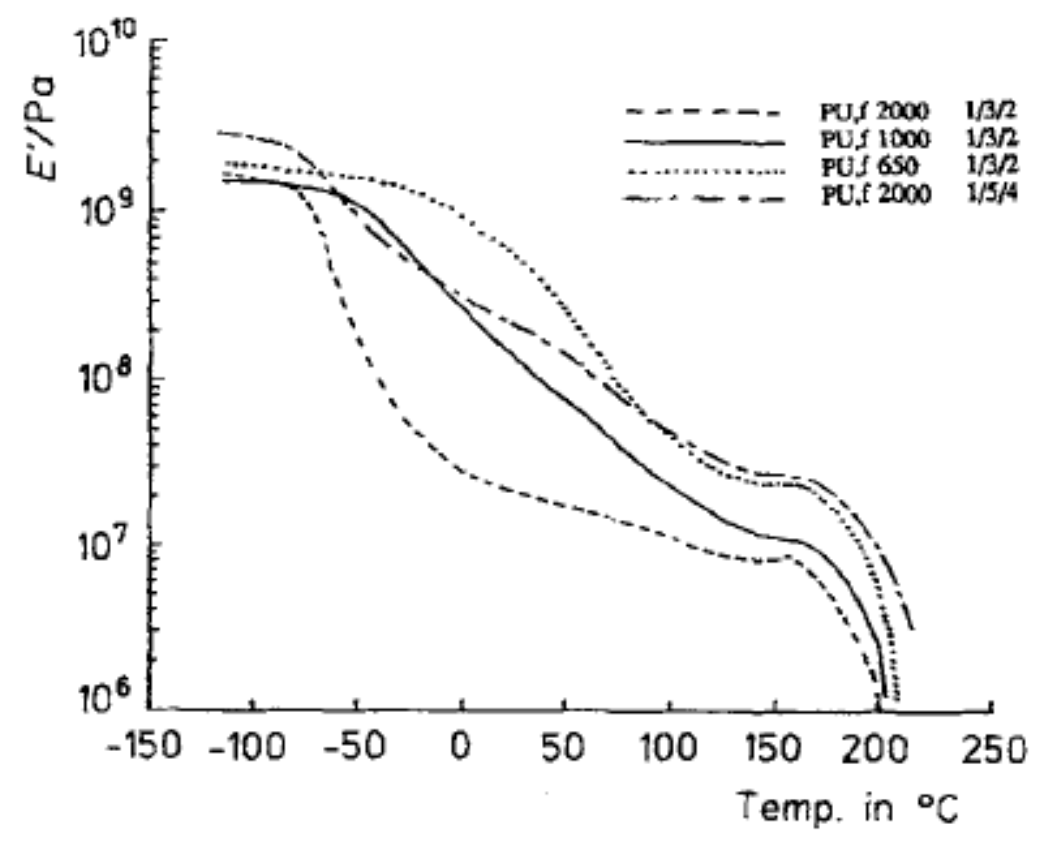

Fig. 7. Dynamic mechanical properties of segmented polyurethanes. Effect of the hard and soft segment length on the storage modulus 


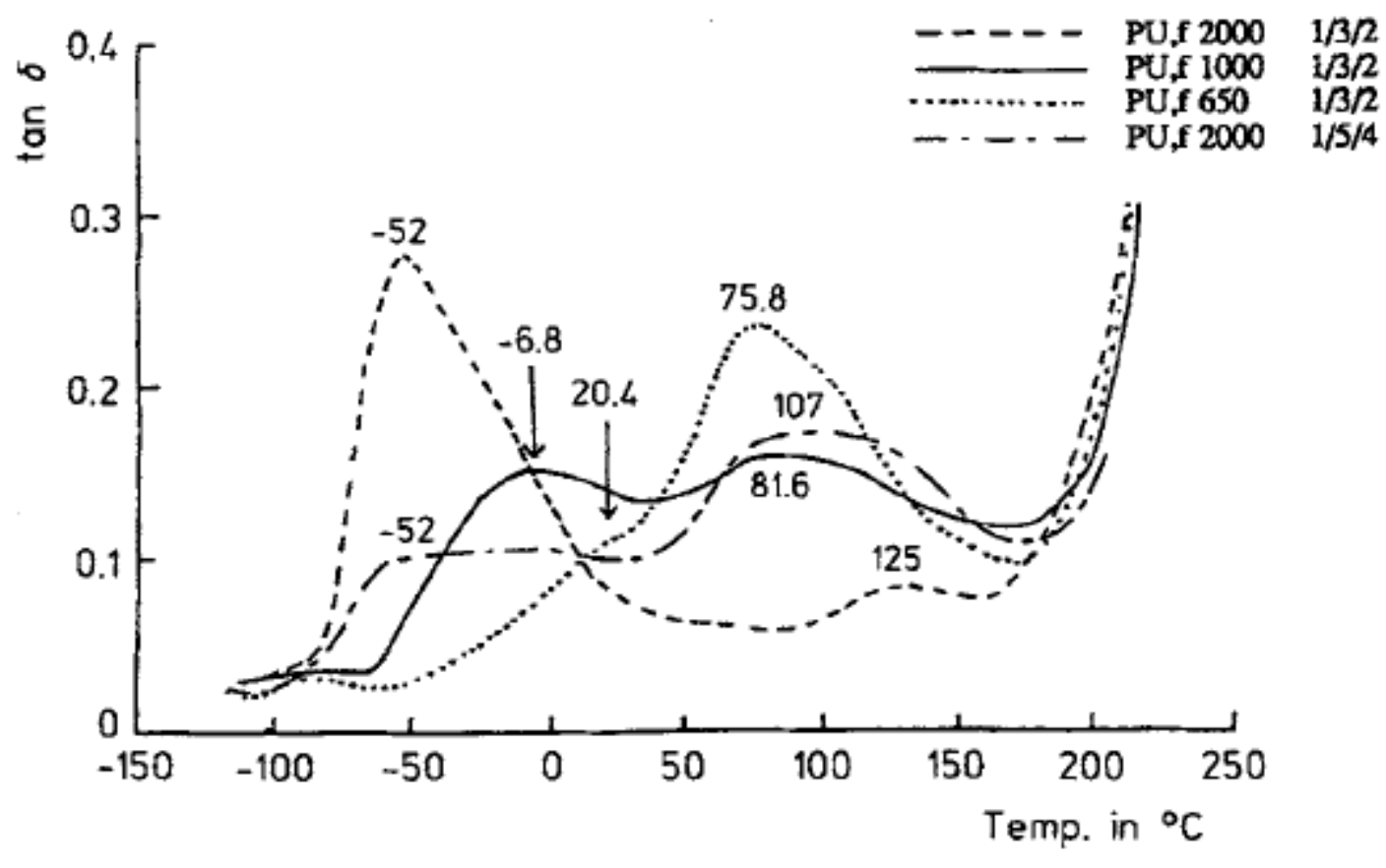

Fig. 8. Dynamic mechanical properties of segmented polyurethanes. Effect of the hard and soft segment length on the loss factor

Tab. 3. Various transition temperatures detected on $\tan \delta$-temp. curves and DSC curves

\begin{tabular}{|l|c|c|c|c|c|c|}
\hline \multirow{2}{*}{ Samples } & \multicolumn{4}{c|}{ Dynamic mechanical analysis } & \multicolumn{2}{c|}{ DSC } \\
\cline { 2 - 7 } & $\gamma$ & $\alpha_{\mathbf{s}}$ & $\alpha_{\mathrm{h}}$ & $\delta^{\text {a) }}$ & $T_{\mathrm{gs}}{ }^{\text {b) }}$ & $T_{\mathrm{mh}}{ }^{\mathrm{c})}$ \\
\hline $\mathrm{PU}, \mathrm{f} 6501 / 3 / 2$ & -85 & 20 & 76 & 190 & - & 212 \\
PU, f $10001 / 3 / 2$ & -90 & -7 & 82 & 190 & - & 220 \\
PU f 2 $0001 / 3 / 2$ & - & -52 & 125 & 190 & -78 & 223 \\
PU f 2 $0001 / 5 / 4$ & - & -52 & 107 & 190 & -80 & 226 \\
\hline
\end{tabular}

a) Onset of the relaxation peak.

b) Glass transition temperature of the soft domains.

c) Melting temperature of the hard domains (minimum of the endotherm).

The $\alpha_{s}$ relaxation can be assigned to the mechanical transition of the soft domain. The relaxation centered at $-100^{\circ} \mathrm{C}$ ( $\gamma$ relaxation) can be ascribed to the motion of the methylene $-\mathrm{CH}_{2}$ - moiety. Although both the hard and soft segment contain this sequence, the major contribution to the $\gamma$ process presumably comes from the soft blocks because of their relatively high amount in the polymer and higher $\mathrm{CH}_{2}$ content. The $\alpha_{\mathrm{h}}$ relaxation is attributed to relaxations within the hard domains. It is considered to be due to micro-Brownian motions of the amorphous phase in the hard domains ${ }^{27)}$. Finally, the high temperature loss process observed at $190^{\circ} \mathrm{C}$ is referred to as $\delta$ relaxation and is assigned in relation with the previous discussion to the order-disorder transition and/or to the melting of hard segment micro-crystallites. 
It appears in Fig. 7 (modulus curves) that the steepness of the slope in the range of the soft segment mechanical transition is less pronounced when $\overline{M_{n}}$ [PTMO] decreases, and at the same time when the hard segment content increases. This is a classical behavior, the immediate consequence of which is a higher modulus at high temperature.

Samples PU, f 1000 1/3/2 and PU f 2000 1/5/4 have nearly the same hard segment amount (respectively 51 wt.-\% and 48 wt.-\%). Their DSC curves (see Figs. 4 and 6) are also very similar. However, the slope of the $E^{\prime}$ vs. temp. curve is less marked for the latter, which has a higher modulus above room temperature. This may be correlated to a higher segregation rate in the case of PU, $\mathrm{f} 2000$ $1 / 5 / 4$, as well as to the length of the hard block. Longer harder blocks could result in more highly aggregated polymer chains and thus to a greater apparent physical crosslink density.

The $\tan \delta$ vs. temp. curves obtained for PU, f 2000,1000 and 650 1/3/2 are displayed in Fig. 8. The intensity and location of the $\alpha_{s}$ relaxation (related to the soft domain) are strongly dependent on the chemical composition of the samples. It is shifted to higher temperatures when the molar mass of the starting PTMO decreases. The evolution of $T_{\alpha s}$ (relative to evaporated samples) with $\overline{M_{n}}$ [PTMO] is thus parallel (although $T_{\mathrm{gs}} \ll T_{\alpha s}$ ) to that of $T_{\mathrm{gs}}$ measured by DSC for moulded samples and attributed to an increased phase mixing when $\overline{M_{n}}$ [PTMO] decreased. Values of $T_{\mathrm{gs}}$ could not be determined by DSC on the evaporated samples PU, $f 000$ and 650. This temperature shift is accompanied by a decrease in intensity and a broadening of the $\alpha_{s}$ loss peak. All these observations may be correlated to the increase in hard segment content when the molar mass of PTMO decreased.

When this hard block content is changed without modifying $\overline{M_{n}}$ i. e. when PU, f 2000 1/3/2 and 1/5/4 are compared, the $\alpha_{s}$ peak is not shifted. But its intensity decreases and it becomes broader when the hard segment length and content increase, presumably because this tends to restrict the motions of the soft segments. Similar results were found with linear segmented polyurethanes based on PTMO, $\mathrm{MDI}$ and $\mathrm{BDO}^{28)}$.

The $\gamma$ relaxation appears only for PU, f 1000 and 650 1/3/2. For samples based on PTMO 2000 it disappears under the wide $\alpha_{s}$ process. Although this $\gamma$ relaxation remains rather weak for the other two samples, it does not seem to be affected by the hard segment content or by the molar mass of the starting PTMO.

The glass transitions relative to the hard domains could generally not be detected on DSC curves, but the $\alpha_{h}$ relaxation nevertheless appears on all $\tan \delta$ vs. temp. curves. As the molar mass of PTMO increases, the $\alpha_{h}$ peak intensity progressively decreases and at the same time shifts to higher temperature. This is consistent with the preliminary conclusions drawn from the DSC results: as phase separation is enhanced, the temperature of the hard domain relaxation $\alpha_{h}$ progressively increases.

Samples PU, f 2000 1/3/2 and 1/5/4 have very similar DSC curves (Figs. 5 and 6), and, according to these calorimetric measurements, seem to have roughly the same segregation rate. However, the $\alpha_{h}$ relaxation occurs at lower temperature for $\mathrm{PU}, \mathrm{f} 1 / 5 / 4$. In fact, the accuracy of the measurement is not as good as for PU, $\mathrm{f} 2000$ 1/3/2 which exhibits quite a narrow peak. Hard segment domains might be more diffuse in the case of PU, $f 1 / 5 / 4$ which presents a much broader molar mass distribution and more isolated (non-chemically linked) hard segments which can possibly act as fillers $\left(I_{\mathrm{p}}=3.8\right.$ instead of 2.6 for PU, f 2000 1/3/2, see Tab. 1). This molar mass distribution and diffuse morphology can broaden the distribution of relaxation times, together with the higher hard segment amount. 
The $\delta$ process has to be related to the occurrence of the ODT process and/or to the melting of some crystalline hard blocks. The ODT is often associated with the drop of approximately one order of magnitude of $G^{\prime}$ (typically from $10^{3}$ to $100 \mathrm{~Pa}$ ) at low frequency (for example $1 \mathrm{~Hz}$, as used here) ${ }^{22,29,30}$ ). However, such a phenomenon would be difficult to detect under our experimental conditions and at the considered temperature. Isothermal frequency-dependent measurements, conducted after various annealing/quench procedures, would probably allow to determine more precisely whether an ODT is actually observed but would once again be difficult to carry out, because of the reversible nature of the urethane bond in this temperature range. Therefore $T_{\delta}$ can only be correlated here with the values of $T_{\mathrm{m}}$ obtained by DSC. Both types of measurements allow the detection of the overall process onset around $190^{\circ} \mathrm{C}$, as depicted in Figs. 3 to 6 and Fig. 8. Besides, the phenomena associated with the peak minima given by DSC measurements are difficult to estimate with the type of mechanical measurements used since at this point the samples started flowing. However, it is worth noting that the final collapse of the modulus occurs above $160-170^{\circ} \mathrm{C}$ i.e. remarkably higher than for the corresponding butanediol-based materials for which it can be found around $130^{\circ} \mathrm{C}^{9}$.

\section{Effect of the nature of the soft segment}

Camberlin and Pascault ${ }^{31)}$ found that for MDI-butanediol hard segments, the segregation rate depends on the nature of the soft segment and decreases from polybutadiene to polyether, i.e. with increasing polarity. In order to check this particular effect with DAS-based hard segments, polyurethanes were elaborated with HPBD exactly under the same conditions as PU 2000 1/3/2.

Samples synthesized either in THF solution or in bulk were all soluble in THF. The number average molar mass obtained for solution polycondensation was $\overline{M_{n}}=26100$ (see Tab. 1) and was thus similar to the corresponding PTMO-based sample, but the distribution was much broader $\left(I_{p}=10\right)$. As the molar mass distribution was even broader for bulk polycondensation, the average molar masses were not calculated in this case.

Representative DSC curves are shown in Fig. 9. The glass transition temperature of the pure HPBD (molar mass 2000 ) is equal to $-45^{\circ} \mathrm{C}^{5}$.

It can be seen in the first scan that the soft domain $T_{\mathrm{gs}}$ is close to that of the pure soft segment. This indicates an important segregation rate, and thus corroborates the results obtained with PTMO-based polyurethanes. The main difference between both soft segments is in fact the $T_{\mathrm{gs}}$ value at the second DSC scan. Indeed, $T_{\mathrm{gs}}$ is lower for HPBD-based polyurethanes whereas it is higher for PTMO-based ones. It was shown above for the latter materials that annealing would promote phase mixing and that with time hard segments would reorganize, leading to a better phase-separated material. In the case of $\mathrm{HPBD}$, annealing can promote demixing due to the increase of mobility at high temperature, and insofar as it is carried out below a possible ODT. 


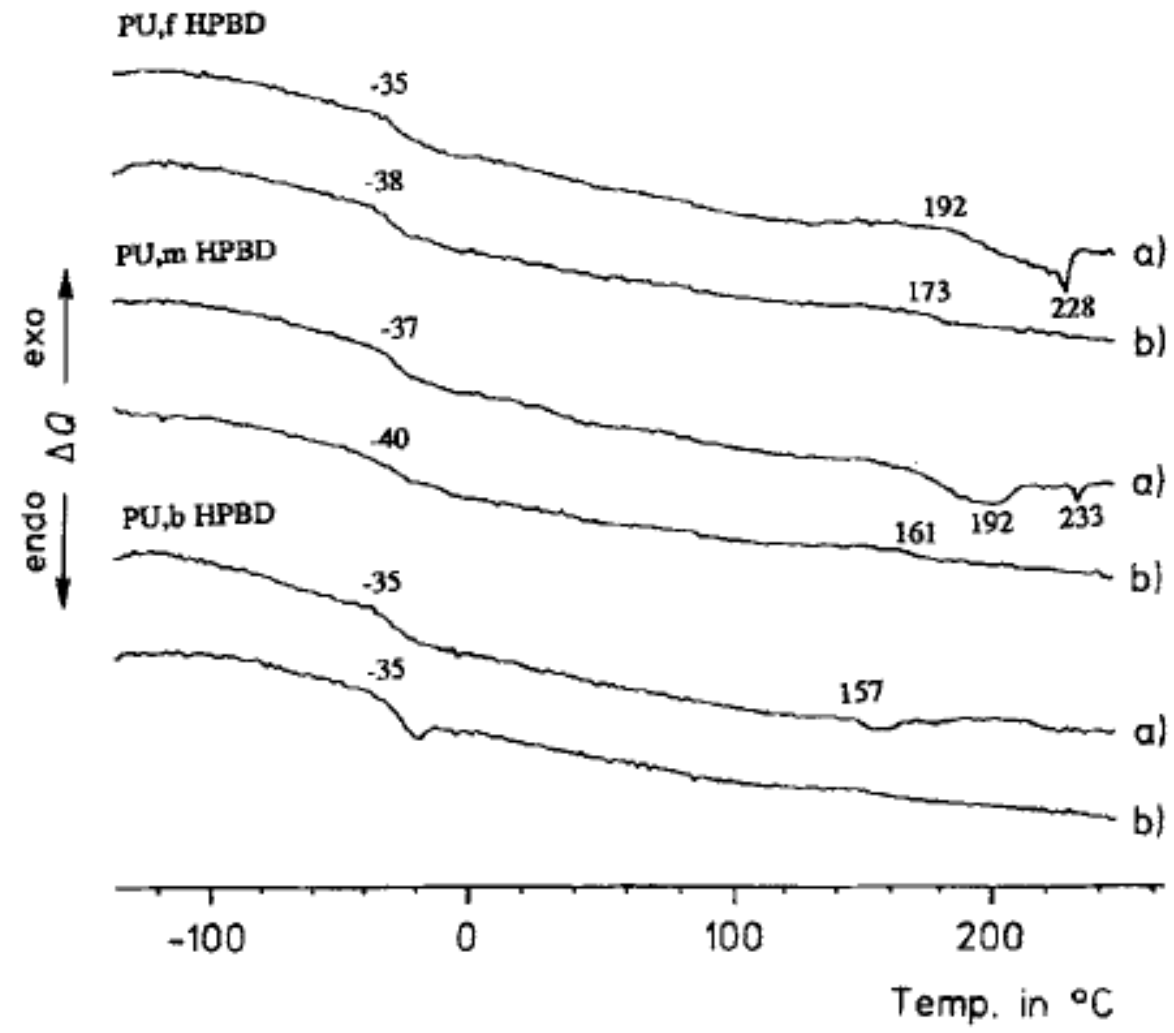

Fig. 9. DSC curves of segmented polyurethanes PU HPBD prepared in different ways; (a) first scan; (b) second scan (after quench)

Concerning the hard domains, the first scans are not quite as clear as those obtained for PTMO-based samples. This phenomenon can be attributed to the broad molar mass distribution. The melting enthalpies $\Delta H_{\mathrm{m}}$ are slightly higher than those measured for the polyether/polyurethanes (for example, $\Delta H_{\mathrm{m}}=7.7 \mathrm{~J} / \mathrm{g}$ for PU, $\mathrm{m} \mathrm{HPBD}$ and $5.5 \mathrm{~J} / \mathrm{g}$ for the corresponding PU, $\mathrm{m} 2000$ 1/3/2), consistently with a higher segregation rate. In the same way, $T_{\mathrm{gh}}$ is detectable for HPBD systems at the second DSC scan. As the heat capacity $\Delta C_{p}$ is very small for the hard microdomains, one may think that the segregation rate is very important, and at least higher than that of PTMO-based polyurethanes where $\Delta C_{p}$ were not detectable. The $T_{\mathrm{gh}}$ values are $173^{\circ} \mathrm{C}$ for PU, f HPBD and $161^{\circ} \mathrm{C}$ for PU, $\mathrm{m} \mathrm{HPBD}$. Both are closer to the value found for the pure hard segment ${ }^{8)}\left(187^{\circ} \mathrm{C}\right)$ than the values found for their PTMO-based counterparts (respectively 156 and $143^{\circ} \mathrm{C}$ ), which reveals the high purity of the hard domains.

Modulus and $\tan \delta$ vs. temp. curves obtained for PU, f 2000 1/3/2 and PU, f HPBD are displayed in Fig. 10. The $\alpha_{s}$ relaxation of the HPBD-based sample is higher than that obtained with PTMO. This result is consistent with the DSC analysis and the higher glass transition of the pure HPBD compared to the pure PTMO. However, as could not be predicted by DSC, the behavior of the HPBD-based material at high temperature is worse: the modulus value at room temperature is lower and flowing occurs at lower temperature $\left(\approx 160^{\circ} \mathrm{C}\right)$, in the same range as $T_{\mathrm{gh}}$ and well below $T_{\mathrm{mh}}$ once again denoting the disastrous effect of isolated (non-linked) hard segments on the material properties and the necessity to have the best control over the involved chemistry. 


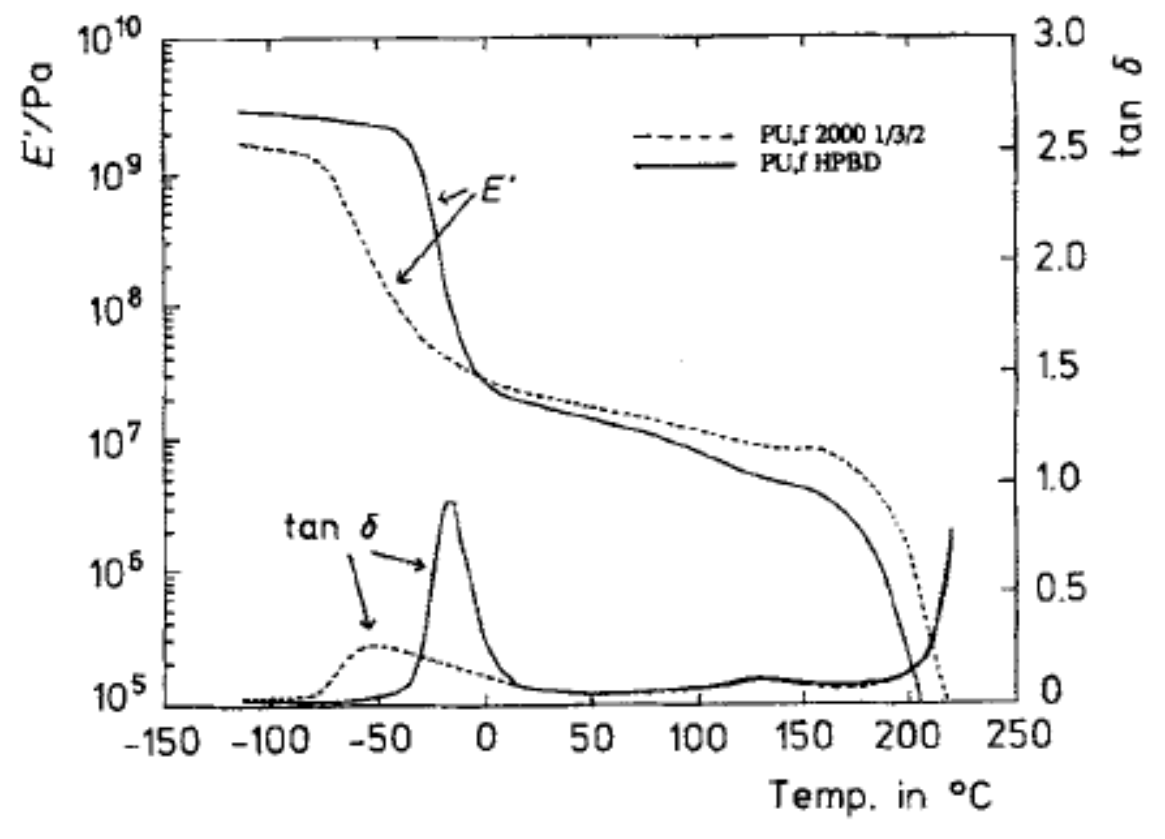

Fig. 10. Dynamic mechanical properties of segmented polyurethanes $\left(\overline{M_{n}}\right.$ [macrodiol] $=2000$; stoichiometry $1 / 3 / 2)$. Comparison between polyether $(--)$ and polyolefin $(-)$ soft segments

\section{Conclusion}

Segmented polyurethanes can be easily obtained through the chain extension of [polyether or polyolefin/4,4'-diphenylmethane diisocyanate] prepolymers with 1,4:3,6-dianhydrosorbitol. Samples present reasonably high molar masses especially when polyether-based polymers are synthesized in catalyzed THF solution. The materials prepared in bulk contain more isolated hard segments and display a more heterogeneous morphology, presumably due to a slower reaction. A greater thermodynamic incompatibility also induces broader molar mass distributions and higher segregation rates when polyolefine soft segments are used.

DSC and dynamic mechanical spectrometry lead to very consistent results. Longer polyether soft segments allow a higher segregation rate and easier crystallization of the soft segments. The thermal annealing associated with a DSC scan $(7.5 \mathrm{~K} / \mathrm{min})$ up to $250^{\circ} \mathrm{C}$ usually induces an increase in the glass transition temperature of the polyether-rich soft phase and demixing between hard and soft domains is rather slow. In the same time, this temperature scan also results in the merging of several hard segment melting endotherm into a unique melting peak at $205^{\circ} \mathrm{C}$, with an onset at $\approx 190^{\circ} \mathrm{C}$. These observations can presumably be associated with the occurrence of an order-disorder transition (ODT) around $180^{\circ} \mathrm{C}$ for the $1 / 3 / 2$ stoichiometry. The same kind of observation can be made on dynamic mechanical spectra, although an additional detailed rheological study would be necessary to confirm the ODT hypothesis. $190^{\circ} \mathrm{C}$ represents the upper limit after which the material starts flowing and can no longer be used. It is a remarkably high value for an otherwise classical segmented polyurethane, since the best values obtained for similar PTMO $2000 / \mathrm{MDI} /$ diol $1 / 3 / 2$ materials are respectively $\approx 130^{\circ} \mathrm{C}$ for $1,4-\mathrm{BDO}$ and $150^{\circ} \mathrm{C}$ for $\mathrm{HQEE}^{9}$.

Acknowledgements: Financial support and chemicals supply from Roquette Frères (Lestrem, France) are gratefully acknowledged. 
1) G. L. Wilkes, R. Wildnauer, J. Appl. Phys. 46, 4148 (1975)

2) G. L. Wilkes, J. A. Emerson, J. Appl. Phys. 47, 4261 (1976)

3) B. Bengtson, C. Feger, W. J. McKnight, N. S. Schneider, Polymer 26, 895 (1985)

4) P. E. Gibson, J. W. C. Van Bogart, S. L. Cooper, J. Polym. Sci., Polym. Phys. Ed. 24, 885 (1986)

5) L. Cuvé, J. P. Pascault, G. Boiteux, G. Seytre, Polymer 32, 343 (1991)

6) Ger. 3111093 (1982), Bayer AG, invs.: H. Meiborg, K. Wagner, J. M. Barnes H. Salzburg; Chem. Abstr. 98, 55354x (1983)

7) D. Braun, M. Bergmann, J. Prakt. Chem. 334, 298 (1992)

8) E. Cognet-Georjon, F. Méchin, J. P. Pascault, Macromol. Chem. Phys. 196, 3733 (1995)

9) V. Darud, PhD Thesis, INSA de Lyon, 1988

10) R. E. Camargo, C. W. Macosko, M. V. Tirell, S. T. Wellinghoff, Polymer 26, 1145 (1985)

11) T. R. Hesketh, J. W. C. Van Bogart, S. L. Cooper, Polym. Eng. Sci. 20, 190 (1980)

${ }^{12)}$ V. Rek, E. Govorcin, Adv. Urethane Sci. Technol. 11, 173 (1992)

13) W. P. Chen, K. C. Frisch, S. W. Wong, Adv. Urethane Sci. Technol. 11, 110 (1992)

14) J. T. Koberstein, R. S. Stein, J. Polym. Sci., Polym. Phys. Ed. 21, 1439 (1983)

15) L. M. Leung, J. T. Koberstein, J. Polym. Sci., Polym. Phys. Ed. 23, 1833 (1985)

16) Z. S. Chen, W. P. Yang, C. W. Macosko, Rubber Chem. Technol. 61, 86 (1988)

17) G. Galland, T. M. Lam, J. Appl. Polym. Sci. 50, 1041 (1993)

18) R. W. Seymour, S. L. Cooper, Macromolecules 6, 48 (1973)

19) R. Bonart, L. Morbitzer, G. Hentze, J. Macromol. Sci., Phys. B3, 337 (1969)

20) J. W. C. Van Bogart, D. A. Bluemke, S. L. Cooper, Polymer 22, 1428 (1981)

21) (a) L. M. Leung, J. T. Koberstein, Macromolecules 19, 706 (1986);

(b) J. T. Koberstein, T. P. Russell, Macromolecules 19, 714 (1986)

22) A. J. Ryan, W. R. Willkomm, T. B. Bergstrom, C. W. Macosko, J. T. Koberstein, C. C. Yu, T. P. Russell, Macromolecules 24, 2883 (1991)

23) A. J. Ryan, C. W. Macosko, W. Bras, Macromolecules 25, 6277 (1992)

${ }^{24)}$ W. P. Yang, C. W. Macosko, S. T. Wellinghoff, Polymer 27, 1235 (1986)

${ }^{25)}$ Y. Camberlin, J. P. Pascault, J. M. Létoffé, P. Claudy, J. Polym. Sci., Polym. Chem. Ed. 20, 383 (1982)

${ }^{26)}$ C. D. Eisenbach, M. Baumgartner, C. Günter, in: Advances in elastomer and rubber elasticity, J. Lal and J. E. Mark, Eds., Plenum Press, New York 1986, p. 51

${ }^{27)}$ H. N. Ng, A. E. Allegrezza, R. W. Seymour, S. L. Cooper, Polymer 14, 255 (1973)

${ }^{28)}$ D. S. Huh, S. L. Cooper, Polym. Eng. Sci. 11, 369 (1971)

29) J. H. Rosedale, F. S. Bates Macromolecules 23, 2329 (1990) 
30) K. Almdal, J. H. Rosedale, F. S. Bates Macromolecules 23, 4336 (1990)

${ }^{31)}$ Y. Camberlin, J. P. Pascault, J. Polym. Sci., Polym. Chem. Ed. 21, 415 (1983) 